\title{
Chapter 16 \\ Citizen Science Case Studies and Their Impacts on Social Innovation
}

\author{
Eglè Butkevičienė, Artemis Skarlatidou, Bálint Balázs, Barbora Duží, \\ Luciano Massetti, Ioannis Tsampoulatidis, and Loreta Tauginienė
}

\begin{abstract}
Social innovation brings social change and aims to address societal challenges and social needs in a novel way. We therefore consider citizen science as both (1) social innovation in research and (2) an innovative way to develop and foster social innovation. In this chapter, we discuss how citizen science contributes to society's goals and the development of social innovation, and we conceptualise citizen science as a process that creates social innovation. We argue that both citizen science and social innovation can be analysed using three dimensions - content, process, and empowerment (impact). Using these three dimensions as a framework for our analysis, we present five citizen science cases to demonstrate how citizen science leads to social innovation. As a result of our case study analysis, we identify the major challenges for citizen science in stimulating social innovation.
\end{abstract}

Keywords Social change $\cdot$ Empowerment $\cdot$ Societal challenge $\cdot$ Digital innovation $\cdot$ Active citizenship - Environmental issues - Air pollution - Nature conservation

E. Butkevičienè $(\bowtie)$

Faculty of Social Sciences, Arts and Humanities, Kaunas University of Technology, Kaunas, Lithuania

e-mail: egle.butkeviciene@ktu.lt
A. Skarlatidou
University College London, London, UK
B. Balázs
Environmental Social Science Research Group (ESSRG), Budapest, Hungary
B. Duží
Institute of Geonics of the Czech Academy of Sciences, Ostrava-Poruba, Czech Republic
L. Massetti
National Research Council - Institute of Bioeconomy, Florence, Italy
I. Tsampoulatidis
School of Architecture, Aristotle University of Thessaloniki, Thessaloniki, Greece
L. Tauginienè
Office of the Ombudsperson for Academic Ethics and Procedures, Vilnius, Lithuania 


\section{Introduction}

Social innovation is a key topic in both policy and academic discourses. Over the last few decades, there has been a special focus on innovation in the European Union (EU) Framework Programmes (FP5, FP6, FP7, and Horizon 2020) as well as in the smart specialisation strategies of each EU country (e.g. social innovation in Lithuania and sustainable innovation in Italy, Hungary, Greece, and the UK). The EU has funded many projects that explicitly or implicitly reference social innovation. Examples include the FP6 project KATARSIS (Growing Inequality and Social Innovation: Alternative Knowledge and Practice in Overcoming Social Exclusion in Europe); the FP7 project SI-DRIVE (Social Innovation: Driving Force of Social Change); and the H2020 projects SIC (Social Innovation Community) and DSI4EU (Digital Social Innovation for Europe). There is also increasing interest in the topic of citizen science. This is mainly reflected in the EU programme 'Science with and for Society' (SwafS) that aims to build capacity and develop innovative ways of connecting science to society (Horizon 2020 n.d.). The EU has already funded many projects related to citizen science; recent examples include Doing It Together Science (DITOs) and the EU-Citizen.Science platform.

A similar discourse around the importance of social innovation also exists in academic research. Social innovation is understood as a new practice or initiative that makes it possible to address societal challenges in various contexts, such as the environment, education, employment, culture, health, and economic development, but also in terms of achieving social goals (Viñals and Rodriguez 2013) and bringing about social change (Dias and Partidário 2019). The literature provides a myriad of approaches towards social innovation, including linking social innovation to sustainable development (Eichler and Schwarz 2019), capacity building (Howaldt et al. 2018), digitisation (Bria et al. 2015), and urban development (Gerometta et al. 2005). Concurrently, citizen science projects are tackling a range of related issues, including the environment and biodiversity (Ries and Oberhauser 2015), sustainable development (Irwin 1995), and health (Wang et al. 2019). These synergies between citizen science and social innovation show their interconnectedness. The connection between these two concepts is twofold: (1) citizen science leading to social innovation and (2) citizen science as social innovation. This chapter explores the latter perspective.

The chapter is composed of four sections. The first section presents the concept of social innovation and its historical development as well as perspectives of social innovation analysis. The second section introduces the conceptualisation of linkage between social innovation and citizen science. These two sections are linked by the argument that both citizen science and social innovation can be analysed using three dimensions - content, process, and empowerment (impact). The third section illustrates how citizen science projects result in the development of social innovations, revealing their content, process, and empowerment (impact) dimensions. The fourth section concentrates on understanding the challenges that hinder the potential of citizen science to create social innovations and providing recommendations and future trends for research. 


\section{Conceptualising Social Innovation: History and Current Developments}

Social innovation is a broad, multifaced concept. Although interest in social innovation is increasing (Eichler and Schwarz 2019), the concept itself is still difficult to define because the meaning of the term 'social innovation' varies across research contexts and disciplines (Rüede and Lurtz 2012). As stated by Phills et al. (2008), it can be 'a product, production process, or technology (much like innovation in general) ... it can also be a principle, an idea, a piece of legislation, a social movement, an intervention, or some combination of them' (p. 39). Although 'social innovation as a phenomenon has been constantly present in the evolution of human societies', the concept of social innovations 'appeared in social science discourses only during the last decades scattered throughout various disciplines as public administration, history, social movements, management, social psychology, economics, and social entrepreneurship' (Cajaiba-Santana 2014, p. 44).

There is a mutual conditionality between social innovation and social change. The potential of social innovations to create social change has been emphasised by many who view social innovation as a driver or a vehicle of social change (CajaibaSantana 2014; Phills et al. 2008). On the other hand, social innovations are shaped by sociocultural, economic, and political environments (Phills et al. 2008). Thus, social innovation is both an object and a driver of social change.

Social innovations should not be understood as antithetical to technological innovations. Many social innovations directly or indirectly use technologies and/or initiate technological innovations. The concept of digital social innovation shows that these two types of innovations co-evolve. Digital social innovations 'inspir [e] digital solutions to social challenges' (Bria et al. 2015, p. 4) and are defined as 'a type of social and collaborative innovation in which innovators, users and communities collaborate using digital technologies to co-create knowledge and solutions for a wide range of social needs and at a scale and speed that was unimaginable before the rise of the Internet' (Bria et al. 2015, p. 9).

There are many ways to analyse social innovations, from generic to specific frameworks. It is common to use a generic framework in innovation analysis, for example, the one suggested by Carayannis et al. (2003) which focuses on four main aspects: (1) the content of innovation; (2) the process of innovation; (3) the context of innovation; and (4) the impact of innovation. While Moulaert et al. (2005) stress three dimensions of social innovations: (1) the content/product dimension ('satisfaction of human needs that are not currently satisfied, either because "not yet" or because "no longer" perceived as important by either the market or the state' (p. 1976)); (2) the process dimension ("changes in social relations, especially with regard to governance, that enable the above satisfaction, but also increase the level of participation of all but especially deprived groups in society' (p. 1976)); and (3) the empowerment dimension ('increasing the socio-political capability and access to resources needed to enhance rights to satisfaction of human needs and participation' (p. 1976)). 
To sum up, the conceptualisation of social innovation shows that public interest, participation, and engagement are crucial for successful social innovation. All these require social capital, public trust, cooperation among citizens, and knowledge co-creation.

\section{Linking Social Innovation and Citizen Science}

The number of social innovation definitions outlined results in a broad variety of terms associated with social innovation in various disciplines. As Putnam (2000) and Grimm et al. (2013) state, in organisational studies, social innovation is framed as social capital, participatory process, and citizen engagement; in territorial studies as community formation and participation; in environmental studies as sustainability; in entrepreneurship studies as social entrepreneurship and co-creation; and in social policy as public engagement. They have one common denominator: inclusivity. Meanwhile, citizen science is also identified with a myriad of terms, such as participatory action research, public participation in scientific research, community-based participatory research, and collaborative civic science (Christopherson et al. 2018; Eitzel et al. 2017); however, citizen science also appears as an umbrella term for such research (see also Haklay et al., this volume, Chap. 2).

Social innovation and citizen science serve similar purposes and are therefore interconnected. Social innovation is aligned with several purposes, such as to encourage diverse change (e.g. social, political, systemic, behavioural); to prompt creativity; to act for the societal good (e.g. solve social problems, improve the general quality of life); and to pave the way for new opportunities (Farmer et al. 2018; Grimm et al. 2013; Lagares Izidio et al. 2018; Nicolopoulou et al. 2017; TsaiHsun 2016). Meanwhile, citizen science aims to solve certain societal issues through co-creation and other participatory approaches as well as to contribute to scientific value (see for more detail Haklay et al., this volume, Chap. 2). Hence, citizen science could be seen from two perspectives. First, citizen science as social innovation, that is, citizen science is an innovative way of carrying out scientific research (e.g. the Zooniverse platform as digital social innovation). Second, social innovation indirectly develops and is an outcome of (some) citizen science projects and complements other significant citizen science impacts. The latter will be comprehensively explored in the next section by presenting five citizen science case studies.

Given the conceptual affinity of social innovation and citizen science, the kernel of both social innovation and citizen science is co-creation. To be more specific, citizen science is a goal-oriented social innovation which aims to build a sustainable and inclusive society (Grimm et al. 2013); this can be via inclusion in scientific discovery (mostly evident in scientist-led citizen science practices) or by fostering sustainability and the societal good (mostly evident in community-led citizen science practices; see Göbel et al., this volume, Chap. 17). Citizen science is also a processoriented social innovation which induces social interaction and self-actualisation (Grimm et al. 2013). Moreover, citizen science fulfils three dimensions - content, 
process, and empowerment (impact) - inherent to social innovation (Hillier et al. 2004; Moulaert et al. 2005). These dimensions fit well with the purposes of citizen science projects; they usually focus on lay people and their contribution to the maintenance of moral values in science as well as to science-produced welfare development (Münkler 2001 as cited in Gerometta et al. 2005). Hence, these appeal to the togetherness of participants, particularly in Extreme Citizen Science which is characterised by a high capacity for social change and involvement in scientific practice in general (da Cunha 2015) (see also Case Study A).

Furthermore, letting the knowledge of citizens penetrate and modify scientific practice creates a more favourable environment for social innovations (Novak et al. 2018; Schäfer and Kieslinger 2016) as well as more transparent solutions (Novak et al. 2018). Given this reasoning, it seems reasonable to marry these two concepts and explore more closely the social innovation impacts of citizen science. Social innovation affects social practices (Schäfer and Kieslinger 2016), and by doing so it transforms into citizen science in various ways: by affecting social structures, academic settings, academic culture, behavioural patterns of scientists, and other processes of scientific practice.

\section{Citizen Science Case Studies and Social Innovation}

In this section, we provide case studies from citizen science projects showing how citizen science relates to the concept of social innovation from different perspectives (see Table 16.1). The first case study describes how Extreme Citizen Science projects and technologies for social innovation provide the methods and tools to support communities all over the world - regardless of local people's background, literacy levels, and cultural and environmental contexts - to collect, analyse, and act on information to address community needs (as identified by them), promote equality, and help achieve environmental sustainability at both local and global scales. The second case study, looking at Dejchej! Brno (Breathe Brno) and Můžu dýchat ('Can I breathe?'), illustrates innovative ways to build inter-sectoral social ties and social capital in the community as well as expand opportunities for the public to use open data in the Czech Republic. The third case study, Fortepan, is an example of how communities can use open data for historical memory in Hungary via different ways of knowing, doing, organising, and framing their activities. The fourth case study, INVOLEN, presents an Italian experience of science and environmental education and shows how citizen science projects can help to build inter-sectoral social ties and social capital. The fifth case study, Improve My City, describes how citizens and government can communicate and collaborate to improve their neighbourhood by reporting local problems and suggesting new ideas through their mobile phones. All the case studies include examples of how citizen science can lead to social innovation. 
Table 16.1 Descriptions of case studies

\begin{tabular}{l|l|l|l}
\hline & Duration & $\begin{array}{l}\text { Geographical } \\
\text { location }\end{array}$ & Stakeholders \\
\hline $\begin{array}{l}\text { A. Extreme Citizen Science pro- } \\
\text { jects and technologies for social } \\
\text { innovation (https://www.geog. } \\
\begin{array}{l}\text { ucl.ac.uk/research/research-cen } \\
\text { tres/excites) }\end{array}\end{array}$ & $5+$ years & Worldwide & $\begin{array}{l}\text { Local communities, } \\
\text { NGOs, scientific experts, } \\
\text { others (depending on the } \\
\text { project) }\end{array}$ \\
\hline $\begin{array}{l}\text { B. Breathe Brno and 'can I } \\
\text { breathe?' - citizen projects pro- } \\
\text { moting air quality }\end{array}$ & $6+$ years & $\begin{array}{l}\text { Brno, Czech } \\
\text { Republic }\end{array}$ & $\begin{array}{l}\text { NGOs, scientific experts, } \\
\text { public institutions, local } \\
\text { governance }\end{array}$ \\
\hline $\begin{array}{l}\text { C. Fortepan - online } \\
\text { crowdsourced photo collection } \\
\text { documenting the twentieth } \\
\text { century }\end{array}$ & $10+$ years & Hungary & $\begin{array}{l}\text { Academic researchers, } \\
\text { amateur researchers, photo } \\
\text { enthusiasts }\end{array}$ \\
\hline $\begin{array}{l}\text { D. INVOLEN - intergenerational } \\
\text { learning for nature conservation } \\
\text { volunteers }\end{array}$ & 32 months & Italy & $\begin{array}{l}\text { Schoolteachers, NGOs, } \\
\text { scientific experts, } \\
\text { researchers, students, } \\
\text { older people }\end{array}$ \\
\hline $\begin{array}{l}\text { E. Improve My City - direct cit- } \\
\text { izen-government communication } \\
\text { and collaboration platform }\end{array}$ & $\begin{array}{l}\text { Initially } \\
3 \text { years, } \\
\text { now } \\
\text { ongoing }\end{array}$ & $\begin{array}{l}\text { Thessaloniki, } \\
\text { Greece (also in } \\
\text { various cities } \\
\text { globally) }\end{array}$ & $\begin{array}{l}\text { Citizens, local authorities, } \\
\text { policymakers }\end{array}$ \\
\hline
\end{tabular}

\section{Case Study A: Extreme Citizen Science Projects and Technologies for Social Innovation}

Context Extreme Citizen Science is defined as a philosophy of 'situated, bottom up practices which take into account local needs, practices and cultures and which work with broad networks of people in order to design and build new devices as well as knowledge creation processes which can truly transform the world'. ${ }^{2}$ Extreme Citizen Science research group (ExCiteS) projects and their associated technologies, developed with the aim of supporting individuals and communities in the collection of traditional ecological knowledge (TEK) and other environmental knowledge to provide the evidence needed to resolve local issues, are an essential requirement for taking further action which can have real impacts.

The two main tools which have been developed for this purpose are Sapelli and Tap\&Map. Sapelli is an open-source data collection app for Android devices, which supports offline and autonomous data synchronisation via SMS and the Internet. Its interface is icon based, and information is organised using hierarchical decision trees, which are codeveloped with local communities during the free, prior, and informed consent (FPIC) and community protocol (CP) processes which are implemented by all ExCiteS projects (for further information on the FPIC and CP

\footnotetext{
${ }^{1}$ As defined on ExCiteS home page: https://www.geog.ucl.ac.uk/research/research-centres/excites
} 
processes, the reader may refer to Tauginienè et al., this volume, Chap. 20). Although Sapelli was developed to support users with limited or no literacy skills, interaction problems with complex hierarchical structures and difficulties in registering input from touching screen interfaces (when users suffer from rough skin and calluses) led to the design and development of Tap\&Map. Tap\&Map is a smartphone app accompanied by a set of cards equipped with near-field communication (NFC) technology. Each card has an icon printed on one side which represents a data item for which information is collected. The user scrolls through the card objects to identify the correct card and taps it on the phone to register the new information.

Box 16.1 provides an overview of the most recent ExCiteS projects, which are currently being implemented around the world.

\section{Box 16.1: ExCiteS Projects}

Kenya: Collecting Data for Indigenous Plants with Maasai Warriors. Maasai warrior communities in Narok county, Kenya, have led an Extreme Citizen Science project since early 2019. One of the greatest threats their community faces is the loss of TEK and increased deforestation in Maasai Mara National Reserve. Sapelli is used to assist communities in collecting and recording TEK related to Indigenous plants; it is the aim of these communities to preserve this knowledge and pass it on to future generations. After the project launched, within a few hours, individuals had gathered over a hundred data items, and since then they have collected thousands of data points with information about the medicinal and other properties of local Indigenous flora.

Namibia: Natural Resource Management and Fighting Illegal Cattle Invasions with Ju/'hoansi. The Nyae Nyae Conservancy in Namibia, officially registered in 1998, has been threatened since local communities have come into contact with agricultural economies, especially due to extensive cattle farming in traditional hunting and gathering grounds. As primary custodians of the conservancy, the Ju/'hoansi use Sapelli and Tap\&Map to collect data to fight illegal cattle invasion in their territory and, more recently, to manage their local community forest resources (Laws 2015).

Brazil: Natural Resource Management for New Conservation Legislation with Indigenous Communities. Mainly situated in Brazil, the Pantanal is the largest wetland in the world with local fishers being totally dependent on it for their daily livelihood. Current legislation for resource management and consumption in the area, which does not consider people's traditional practices, led to the fishers' physical and economic displacement. Sapelli has been used with local communities since 2014, who collect data about the use of natural resources and their management strategies. The data collected provided evidence that Indigenous practices are sustainable and, as a result, local people have been officially recognised as a traditional community giving them the 
Box 16.1 (continued)

right to protect their livelihoods using their traditional practices (Chiaravalloti 2019).

Cameroon: Supporting Baka Communities Tackle Illegal Wildlife Crime and Animal Monitoring. The Baka hunter-gatherers and Mbulu farmers of Cameroon live in the forest in Dja Biosphere Reserve, which hosts a large variety of plants and animals to support their livelihood but is currently being depleted by illegal wildlife trade and extractive industries. Current conservation legislation excludes Indigenous communities and their knowledge and turns them into conservation refugees. Sapelli has been used, since 2015, to collect data about illegal wildlife crime and animal monitoring, which at the moment is the only viable solution to obtain reliable data to inform effective forest management in the future (Hoyte 2017).

Link to Social Innovation An increasing number of people, driven by a sense of responsibility and environmental awareness, are interested in citizen science activities to protect the wider planet's ecosystem and its natural resources. At the same time, Western beliefs that techno-scientific innovations, complex legislation, international agreements, and Eurocentric conservation models are the solutions to create a sustainable future have slowly started to crumble. Increasing attention is being focused on TEK for its potential to significantly contribute to the sustainability debate; as has been recognised within Indigenous communities for millennia, it is this kind of knowledge that has enabled people to rely on their local environments and survive for thousands of years. TEK is mostly undocumented, and researching it requires zooming into remote local environments to understand how Indigenous peoples interact with them, one of the aims of the ExCites projects. By listening to community problems and providing the appropriate tools and methods to collect data in the most remote areas of our planet, Extreme Citizen Science has a direct impact on conservation, natural resource management, and environmental governance above all in terms of promoting equality, just forest management, and empowering local communities to take ownership of and address their issues of local (or global) concern. ExCiteS projects engage with extremely marginalised communities, often ignored by the global sustainability debate, and by doing so, they improve people's awareness of local environments and knowledge and our responsibility to protect them. They further build community capacity and individuals' skills in the use of technology, project management, and scientific literacy, utilising local but also global perspectives in identifying solutions to fit the local cultural, social, and environmental contexts. 


\section{Case Study B: Breathe Brno and 'Can I Breathe?'- Citizen Projects Promoting Air Quality}

Context The quality of the air influences the health and well-being of all living beings, and it is a particular concern for those living in urban environments. European countries are required to follow national and EU air quality directives (2008/50/EC Directive on Ambient Air Quality and Cleaner Air for Europe). Unfortunately, many European cities are either not able to manage air quality satisfactorily or the citizens themselves are not willing to reduce their personal emissions (or they may not be aware of how to do so). Brno is one of the many European cities which exceed the air pollution limits of particulate matter (PM) and nitrogen oxides (NOx) (CHMI 2019). Within this framework we provide a case study of projects using citizen science to address this issue.

Two citizen science projects, that are dealing with air quality, work in collaboration with the city of Brno. First is Breathe Brno, which started as a bottom-up informal civil initiative to highlight the environmental and health consequences of air quality (focusing on PM) in Brno. Breathe Brno was initiated in 2013 by several young mothers with small children with the aim of drawing municipality attention to the problematic air conditions and the breaching of air pollution limits in Brno. They focused on making this problem visible to the public and stimulating the municipality to address it. Another related project is 'Can I breathe?', coordinated by the NGO Nesehnutí, with a similar aim, although more oriented towards air quality in general.

Link to Social Innovation The content of the projects is linked to social innovation in several aspects. The mothers were attempting to resolve a very complex issue with limited resources, but they decided to cooperate with other NGOs and scientists to raise public awareness and put pressure on local governmental actors to take action. Their aim was to address the problem of the limited official information provided by the authorities. They created web pages with simple graphics pointing out the actual daily levels of PM in several parts of Brno, based on open data from the Czech Hydrometeorological Institute (CHMI), derived from 12 meteorological stations. The availability of this information itself has an important impact as citizens can now better evaluate whether the pollution levels are acceptable but also which public spaces of Brno are more 'pollution-safe' for taking a short walk (e.g., with a baby in a pram), carrying out exercise, or any other type of outdoors activity. The citizens who participated in the project connected their web page to Nesehnutí's, which manages a more complex map of air pollution in Brno ('Can I breathe?') based on other open data sources. This map is further enhanced by a do-it-yourself software application simulating daily predictions of air pollution hour by hour. These applications go beyond the standard provision of an air quality index. Both projects also provide additional information about the issue, ask the public to submit their own experiences, and signpost other ways of potential public participation. 
From the process's point of view, at first the mothers' activity was not taken seriously by the municipality of Brno, despite their efforts to gather evidence of air quality measurements at several official spots. The turning point was when they started to cooperate with NGOs such as Nesehnutí and the Centre for the Environment and Health and when they invited the internationally respected air pollution expert Kaare Press-Kristensen to verify their concerns. Based on the recommendation of several volunteers, experts made additional measurements in other locations of the city, and this provided further scientific evidence about the serious state of the issue and initiated wider public discussion. Since then, several additional measurements of air pollution (PM, NOx) have been realised with the help of volunteers (the latest in 2019, covering 34 new places).

Several attributes of ongoing social empowerment (impact) were identified. First, the public's understanding of air pollution and its health and climate change consequences has been increasing. Women, especially those leading the project, were appreciated as relevant stakeholders for negotiating and dealing with this urban health issue. As a result, civic initiatives are now promoting a set of practical measures - such as the use of public transport, cycling and effective cycle routes, and the establishment of low emission zones by limiting the entry of cars to the city centre - to be implemented in the Brno local plan. It seems that citizens' interest in this issue has increased. For example, people now question in which parts of Brno they would buy a house due to the air pollution or where they can buy cheap metres to evaluate the local environmental conditions themselves. The issue is now frequently discussed in local media. Moreover, Nesehnutí recently initiated a new citizen-driven participative web page called HejbejBrno (Move Brno), focusing on a wider spectrum of urban issues, transport issues, and public spaces. The pressure that these projects put on the municipality, together with the obligation to abide by EU air quality directives, has stimulated several measures, although their actual impact is yet unclear. Currently, every measure undertaken by the municipality, for example, the preparation of various strategic documents and plans dealing with air quality, is carefully monitored by civic initiatives. Recently, around 30 civic initiatives joined forces via the Brno Climatic Coalition Association with the shared goal of improving the air quality in Brno. It proves that the environmental movement in Brno has become a respectable partner in democratic society, as continually assessed by researchers dealing with environmental and civic initiatives and their impacts in CEE countries (i.e. Fraňková et al. 2015).

\section{Case Study C: Fortepan - Online Crowdsourced Photo Collection Documenting the Twentieth Century}

Context Citizen science practices in Central and Eastern European (CEE) countries are relatively new but already manifest a range of social innovation dynamics and agency. Some are linked to international projects or umbrella organisations that 
coordinate knowledge exchange focused on global environmental issues. Others connect to regional platforms, for example, the European Citizen Science Association or EU-funded $\mathrm{H} 2020$ projects that enable transnational networking, primarily for predefined societal challenges. National-level organisations also embark on citizen science journeys to collect data, raise awareness, and monitor specific issues. Finally, local grassroots movements and community-based activities, often in multiactor settings, also engage in public participation in research, although these are not always explicitly considered citizen science. In this qualitative case study approach, the theory of transformative social innovation (TSI) (Avelino et al. 2015; Haxeltine et al. 2016) is used to understand the emergent field in Hungary and the social configurations that create transformations in global challenges. According to TSI theory, the practice of social innovation comprises heterogeneous social-material collectives. It has human and non-human elements and can be perceived with cognitive, material, social, and normative dimensions (Haxeltine et al. 2016). Social innovation processes are transformative as they include new ways of knowing, doing, framing, and organising that challenge established, dominant institutions.

The case study, Fortepan, is an open-source curated online photo archive launched in 2010 in Hungary. Started as a private collection by two high school friends, today Fortepan is the largest photo archive with nearly a hundred thousand freely downloadable annotated images. It features pre-1990 private photo collections (before the mass proliferation of digital photography) curated by the founder, Miklós Tamási, and maintained by volunteers. Fortepan solicits private donations; no public money is involved. The project collects citizens' good-quality amateur, private photos and makes them publicly available under the Creative Commons 3.0 licence in an easily searchable web interface. The primary mission is not scientific research or the contextualisation or interpretation of the photos but conservation.

Nevertheless, anyone can interpret the photos, and Fortepan is, therefore, recognised as an excellent research opportunity for professionals who can uncover unexpected photos with a simple thematic search. In essence, Fortepan provides a common digital heritage that anyone can use in any way, even for commercial purposes. Fortepan photos are often used by academics to illustrate a point and for book covers. Literary works have also been inspired by the rare and often enchanting old photos. In addition, Fortepan has created photo books and calendars on specific themes (coffee houses, urban environments, women) that build on the open access archive of pictures of everyday life.

Link to Social Innovation Fortepan has a number of socially innovative elements; we will explore their transformative aspects. By experimenting with volunteerism and community management approaches, Fortepan generates new knowledge on the history of everyday life. By collecting and making old private photos publicly available and building a collective memory, while being careful not to undermine professional photographers or museum professionals, Fortepan is experimenting with new ways of doing. By positioning private photos as part of our collective memory, emphasising sharing as a pathway to the future, and developing a scientifically sound and free resource base, Fortepan is framing photo archiving in a novel 
way. New ways of organising are also visible: volunteerism, engaging amateurs to provide photos, building on informality, grassroots, and non-market-based cooperation with public collections and news media.

In conclusion, Fortepan created a publicly accessible digitised visual collection that can help us to represent our collective memory. It provides enhanced public participation; it is a prefiguration of a citizen science project but has the potential to turn into one.

Fortepan is mobilising the recent interest in the history of everyday. Fortepan volunteers spend several hours a day deciphering the photos from private family collections using an Internet forum to crowdsource and interpret the data necessary to identify details. The collection is unique as public collections and museums do not provide open access, high-quality, and royalty-free photos in Hungary. Moreover, such archival collections are mostly comprised of propaganda photos and press photos, which are created for a particular institutional purpose and do not reflect the viewpoint of everyday people.

\section{Case Study D: INVOLEN - Intergenerational Learning for Nature Conservation Volunteers}

Context Sustainable development and the reduction of human pressure on the environment are strategic challenges that require a dramatic change in our behaviour to avoid depleting the world's resources available for future generations. An important role can be played by schools through science and environmental education formats that foster active citizenship. Citizen science projects can provide a method that is particularly effective with younger students (Locritani et al. 2019). Moreover, education that includes activities focusing on local territory (place-based education) stimulates proactive behaviour and responsibility (Schild 2016), while integrating ICT in these activities increases students' interest and involvement. Within the framework of INVOLEN (Intergenerational Learning for Nature Conservation Volunteers), funded by the Lifelong Learning Programme of the European Union (2012-2015), a learning model was developed and tested in Italy, Greece, France, Hungary, and Slovenia. The model brings together students and elders and promotes both mutual respect and social cohesion between different generations in voluntary activity for nature protection and conservation (Ugolini et al. 2016). A focus group (of students and elders, guided by a facilitator, working with experts like environmental guides, teachers, and researchers) is convened to learn more about a local protected area and promote and protect the site by following a methodology structured in six units (for details see Papageorgiou et al. 2015). We will explore the multiscale benefits reported by a focus group in Livorno, Italy, comprised of elders and students, aged 12-13, also referencing pre- and post-project questionnaires completed by all participants (Ugolini et al. 2016). 
Link to Social Innovation From the content point of view, a focus group, composed of students, elders, and environmental and ICT experts, selects and works on a local area of interest (e.g. a nature area or green urban area). Then the focus group applies the INVOLEN methodology (for details see Papageorgiou et al. 2015) that consists of indoor and outdoor meetings led by a facilitator. In the first stage, elders and experts share their knowledge about historical, social, economic, and ecological features of the area. Then the whole group participates in field trips to undertake practical actions for the conservation of the area (e.g. waste cleaning and marking trails), and students document the experience with photos, videos, and storytelling. The collected material and the resulting stories constitute the basis for the creation of a location-based game (LGB) aiming to promote the area (Papageorgiou et al. 2015).

INVOLEN successfully involved students in taking care of their local areas by increasing awareness of nature and curiosity for experiential knowledge, fundamentals of citizen science. Therefore, even though this project is not a typical citizen science project, it contributes to it by transferring the knowledge of the local territory to the local community and the general public through the action of stakeholders of different ages and cultural backgrounds. ${ }^{2}$ INVOLEN also involves elders in voluntary activities. Moreover it targets improvement of communication skills and mutual respect by fostering intergenerational experiences. Therefore it promotes a sense of community both at the territorial and intergenerational levels, using a known environment to trigger a sense of belonging and reinforcing understanding between generations regarding their skills.

The main subject of the process dimension is the focus group that works in formal and informal settings, changing the roles and leadership of participants according to the topic. Elders led the meetings in which they shared their knowledge connected to stories about the traditional uses of nature but also personal experiences and hobbies. The science and environmental experts brought their experience of the natural environment and its threats. Students were the main beneficiaries because they gained knowledge of the environmental, cultural, and social value of the area. However, during LGB creation and development, students became leaders and supported elders in the technological part of the project, thanks to their confidence in the use of ICT tools and apps. The group, especially the students, found a space for expressing their creativity and learnt to manage competences needed for working in groups (e.g. codesign and communication).

From the social empowerment (impact) dimension, elders improved their selfconfidence and communication with the students. They also became more familiar with ICT and aware of the potential of digital devices. Students were encouraged to be more involved in active nature protection and showed interest in learning more about conservation issues and solutions for their local area. Moreover, elders benefited from social inclusion by building new relationships, reducing isolation, and feeling useful. In addition, the capacity of NGOs, schools, and adult education institutions to provide innovative education improved, as did the qualifications of

\footnotetext{
${ }^{2}$ See http://www.involen.eu/en/learning-tools-resources
} 
their staff. Therefore, there is great potential in terms of social innovation because the model improves awareness of local, environmental, and social issues, thus promoting active citizenship, and fosters the application of science thinking and ICT tools to propose solutions to tackle these issues. The model had a strong impact in other communities (30 groups from 5 countries) that applied it during the project. Later on, the model was also successfully applied in several national and international projects such as an ongoing ERASMUS+ project (Daylighting Rivers) where LGB was integrated into an inquiry-based learning model (Pedaste et al. 2015) to study environmental issues related to rivers in urban areas (Ugolini et al. 2019). See also Kloetzer et al. (this volume, Chap. 15) and Hidalgo et al. (this volume, Chap. 11) for additional experiences that relate to social innovation and education and learning.

\section{Case E: Improve My City - Direct Citizen-Government Communication and Collaboration}

Context The inclusion of new innovative solutions for more direct, structured, and transparent communication between citizens and government has been pursued by an increasing number of cities in recent years. Among these cities, Thessaloniki chose Improve My City (IMC) as its official application for reporting non-emergency issues with the goal to engage citizens by inviting them to support their common collective effort for better everyday living. This case study explains how IMC is actively being used in the municipality of Thessaloniki as a citizen science application (Tsampoulatidis et al. forthcoming) and how it promotes the development of social innovation and describes its societal impact by analysing the collected citizens' data from the last 4 years (as of late 2019).

IMC is a free and open-source software platform that facilitates citizens to directly report local issues about their neighbourhood such as potholes, trash, graffiti, illegal advertising, etc. but also to promote new ideas, for example, new parking spots, suggesting the renovation of abandoned buildings and calling for charity actions, just to name a few. IMC is also available for smartphones to further empower citizens to report issues while on the move.

Link to Social Innovation By using IMC, citizens are becoming the eyes of the city, in the sense that they can act as living sensors of their neighbourhood, and from the content perspective, they can directly inform the local authorities about their problems and ideas, allowing city officials to perceive citizens' concerns from a different point of view. The reported issues are automatically forwarded to the appropriate departments in the municipality to monitor, manage, and schedule their settlement. Through IMC, the municipality interacts with the citizens publicly in a highly transparent manner since all responses and actions taken in addressing the issues are recorded and become available online for everyone to see, comment on, and support (by voting on them). This, according to Tsampoulatidis et al. (2013, 
p. 839), adds a social dimension to the collected content and stimulates public participation. As of late 2019, almost 60,000 issues have been submitted by approximately 13,000 registered users, resulting in more than 200,000 recorded actions (e.g. status change) and about half a million exchanged emails. Importantly, after the analysis of the collected data, some unforeseen collaborative actions have also emerged. Citizens have teamed up by creating action groups focusing on specific areas of the city such as the historic centre or targeting specific issues such as blocked pathways for wheelchair users. These examples clearly denote that IMC encourages collaboration and facilitates 'togetherness' of community members in developing social innovation.

An interesting fact that highlights the process dimension of social innovation in IMC is that transparency and interactivity between citizens and government result in high levels of appreciation, especially from users who get feedback on their actions (e.g. comments or positive votes). Examination of the app's analytics also shows that users who receive feedback keep submitting new issues and spend more time using the app. Moreover, there are recorded cases where citizens have helped the authorities in the process of resolving an issue by giving suggestions and ideas or even offering volunteer work (e.g. gardening).

As for the empowerment (impact) dimension, IMC's direct impact is twofold: (1) local authorities are informed about actual issues in real time, even for remote areas and neighbourhoods, which otherwise, following the traditional approach, would take longer to be spotted; and (2) the collected data is processed and analysed (via IMC analytics that provide smart interactive visualisations and maps) and made available to policymakers, local administrations, NGOs, and various communities and groups to support evidence-based decision-making. Equally important is the indirect societal impact. Collaboration reinforces the sense of community service, increases local authorities' responsiveness, and strengthens trust in the government. Moreover, IMC promotes transparency, cultivates a participatory culture, creates communities, enhances and encourages citizen-government communication and collaboration, and produces open data that can be used by all. Furthermore, economic impact is achieved by reducing functional costs via effective monitoring and scheduling, while environmental impact is attained by heavily reducing paperwork and unnecessary travel.

\section{Challenges, Recommendations, and Future Trends}

In this section, we briefly present some of the most critical challenges from the implementation of the case studies presented in this chapter and make recommendations to maximise social innovation impacts in similar contexts.

Narrow disciplinary attitudes and the presumptions which surround domain specificities often limit the effective assessment of societal problems and subsequently the solutions developed to address them using citizen science. For most citizen science practices to succeed and to maximise their social innovation impacts, 
interdisciplinary implementation approaches can be beneficial, as they have the potential to expand understanding of societal and scientific problems in specific contexts and therefore support the design of novel solutions which can be used to address them.

Community-led or bottom-up projects in citizen science are now commonly used to address specific problems that communities are facing using scientific approaches and tools (e.g. projects for collecting data and monitoring noise or air pollution). It is not uncommon for these problems to be entangled in local politics, which can be difficult to expose, or for previous collaborations to have resulted in distrust. We, therefore, suggest that starting by building trust with local communities is of utmost importance for the success of any citizen science project and for maximising its social innovation impact. For example, in Case Study A, to build trust, researchers spent significant time in the field developing community protocols and lived with local communities to understand people's needs, cultural contexts, and ways of living. Similarly, in Case Study E, in order to promote transparency and trust, the local authorities in Thessaloniki recently decided to record offline issues through the workflow of IMC by dedicating employees to input the data, which is a good practice to ensure inclusion.

While citizen science activities may attract people of all ages, backgrounds, and interests, the focus so far has been on the limited demographic profile of Western, educated, industrialised, rich, and democratic (WEIRD) societies (Dourish 2015). For everyone to benefit from citizen science and create social innovation impacts globally, it is important that there is an increase in the number of citizen science projects which engage marginalised, underrepresented, and hard-to-reach communities and groups. For example, although they are less popular, citizen science projects which target communities in developing countries, similar to those presented in Case Study A, can result in capturing local Indigenous knowledge which has an important role to play in the global environmental sustainability agenda. Similarly, Case Study B describes the engagement of a social group that is usually underrepresented - women with small children.

Support at the policy level is also a major factor in the success of citizen science projects in order to achieve social innovation. Projects primarily require that officials accept the fact that all actions taken (or not taken) can be openly and transparently discussed by citizens (Case Study B). There is evidence that the types of data collected may influence the way legislation is shaped to benefit local communities (Case Study A), but this is a challenging process with extremely long timescales, personal and political hurdles, and other barriers. To address these issues, we need to strengthen the promotion of citizen science and its recognition at policy level.

Last but not least, with the increasing use of digital tools to support and enable citizen science activities, it is frequently overlooked that technological intervention design should not only reflect the scientific needs but should also suit local contexts of use and be intuitive and easy to use if they are to succeed in their desired goals and impacts. With many examples of projects failing on that front, it becomes evident that the assumption that usability is 'a built-in property' of any technology which is used to support citizen science is false. We, therefore, suggest that designing 'user- 
friendly' technologies to support participants in citizen science activities becomes an integral element for consideration and evaluation in citizen science practice.

This chapter provides some insights and illustrations on how citizen science can lead to social innovation. We emphasised that, in using citizen science, it is important to create innovative milieu through learning, networking, cooperating, and addressing communities' challenges (Crevoisier 2004).

We have to consider further how to expand the understanding of applying citizen science and its technologies so that all communities are involved and empowered through participating in citizen science projects and fully benefit from their anticipated social innovation impacts. Responsible research and innovation (RRI), mostly relevant to the EU, can be seen as one of the preconditions for enabling social innovation in citizen science. The European Commission lately defined RRI as 'an approach that anticipates and assesses potential implications and societal expectations with regard to research and innovation, with the aim to foster the design of inclusive and sustainable research and innovation' in a co-creative spirit (Responsible Reasearch \& Innovation, n.d.). Particular efforts should be directed towards gender inclusiveness and establishing citizen science as an umbrella for public engagement and science education (e.g. all societal actors should be targeted, including national and local policymakers, citizens, and so forth, and communication should be informed by evidence). This is also a way to demonstrate the social responsibility of scientists and scientific organisations towards citizens alongside carrying out research not only in an innovative way but also with integrity, transparency, and openness.

Thus, schools and other educational and scientific establishments are suitable spaces 'to start fostering citizens' autonomy and responsibility for change through lifelong learning' (Schäfer and Kieslinger 2016, p. Y02-9) and to develop skills to contribute to social innovation through science education and sensitising local and global issues, for example, in health, environment, and culture. This can be achieved by replicating and partially translating social innovation, which will allow social innovation to be both recognised and scaled up (Mulgan 2006). This will help consider ethical and democratic values as well as to develop citizens' commitment to social responsibility (Lagares Izidio et al. 2018). Therefore, the focus on schools and education and science organisations as hubs for citizen science and social innovation should be considered more intensively in the future.

\section{References}

Avelino, F., Dumitru, A., Longhurst, N., Wittmayer, J., Hielscher, S., Weaver, P., et al. (2015). Transitions towards new economies? A transformative social innovation perspective. TRANSIT working paper 3. TRANSIT: SSH.2013.3.2-1 Grant Agreement No: 613169. http://www. transitsocialinnovation.eu/resource-hub/transitions-towards-new-economies-a-transformativesocial-innovation-perspective 
Bria, F., Gascó, M., Baeck, P., Halpin, H., Almirall, E., \& Kresin, F. (2015). Growing a digital social innovation ecosystem for Europe: DSI final report. London: Nesta. https://media.nesta. org.uk/documents/dsireport.pdf.

Cajaiba-Santana, G. (2014). Social innovation: Moving the field forward. A conceptual framework. Technological Forecasting and Social Change, 82, 42-51.

Carayannis, E. G., Gonzalez, E., \& Wetter, J. (2003). The nature and dynamics of discontinuous and disruptive innovations from a learning and knowledge management perspective. In L. V. Shavinina (Ed.), The international handbook on innovation (pp. 115-138). Oxford: Elsevier.

Chiaravalloti, R. (2019). The displacement of insufficiently 'traditional' communities: Local fisheries in the Pantanal. Conservation and Society, 17(2), 173-183.

CHMI. (2019). Informace o kvalitě ovzduši v ČR. http://portal.chmi.cz/files/portal/docs/uoco/web_ generator/exceed/index_CZ.html. Accessed on 10 Nov 2019.

Christopherson, E. G., Scheufele, D. A., \& Smith, B. (2018, Spring). The civic science imperative. Stanford Social Innovation Review, pp. 46-52.

Crevoisier, O. (2004). The innovative milieus approach: Towards a territorialized understanding of the economy? Economic Geography, 80(4), 367-379.

da Cunha, R. (2015, September). Are you ready for citizen science? Spokes (11). http://www.ecsite. eu/activities-and-services/news-and-publications/digital-spokes/issue- $11\{\ \#\}$ section=sectionindepth $\backslash \&$ href=/feature/depth/are-you-ready-citizen-science

Dias, J., \& Partidário, M. (2019). Mind the gap: The potential transformative capacity of social innovation. Sustainability, 11, 4465.

Dourish, P. (2015). Forward. In N. J. Bidwell \& H. Winschiers-Theophilus (Eds.), At the intersection of Indigenous and traditional knowledge and technology design (pp. vii-x). Santa Rosa: Informing Science Press.

EC (European Commission). (n.d.). Responsible research \& innovation. https://ec.europa.eu/ programmes/horizon2020/en/h2020-section/responsible-research-innovation. Accessed on 21 May 2020.

Eichler, G., \& Schwarz, E. (2019). What sustainable development goals do social innovations address? A systematic review and content analysis of social innovation literature. Sustainability, $11(2), 522$.

Eitzel, M. V., Cappadonna, J. L., Santos-Lang, C., Duerr, R. E., Virapongse, A., West, S. E., et al. (2017). Citizen science terminology matters: Exploring key terms. Citizen Science: Theory and Practice, 2(1), 1. https://doi.org/10.5334/cstp.96.

Farmer, J., Carlisle, K., Dickson-Swift, V., Teasdale, S., Kenny, A., Taylor, J., et al. (2018). Applying social innovation theory to examine how community co-designed health services develop: Using a case study approach and mixed methods. BMC Health Services Research, 18, 68.

Fraňková, E., Dostalík, J., \& Škapa, R. (2015). Behavioural views in environmentalism. Sociální studia, 3, 5-8.

Gerometta, J., Häussermann, H., \& Longo, G. (2005). Social innovation and civil society in urban governance: Strategies for an inclusive city. Urban Studies, 42(11), 2007-2021.

Grimm, R., Fox, C., Baines, S., \& Albertson, K. (2013). Social innovation, an answer to contemporary societal challenges? Locating the concept in theory and practice. Innovation: The European Journal of Social Science Research, 26(4), 436-455.

Haxeltine, A., Avelino, F., Pel, B., Dumitru, A., Kemp, R., Longhurst, N., et al. (2016). A framework for transformative social innovation. TRANSIT working paper \# 5. TRANSIT: EU SSH.2013.3.2-1 Grant Agreement No: 613169. http://www.transitsocialinnovation.eu/ resource-hub/a-framework-for-transformative-social-innovation-transit-working-paper-5.

Hillier, J., Moulaert, F., \& Nussbaumer, J. (2004). Trois essais sur le rôle de l'innovation sociale dans le développement territorial. Géographie, économie, société, 6(2), 129-152.

Horizon 2020. (n.d.). Science with and for society. https://ec.europa.eu/programmes/horizon2020/ en/h2020-section/science-and-society. Accessed on 15 Dec 2019. 
Howaldt, J., Kaletka, C., Schroder, A., \& Zirngiebl, M. (2018). Atlas of social innovation - New practices for a better future. Dortmund: TU Dortmund University Press.

Hoyte, S. (2017, 1 March). Indigenous Baka hunters vs. the illegal wildlife trade. Hunt and gather. https://simonhoyte.wordpress.com/2017/03/01/indigenous-baka-hunters-vs-the-illegal-wild life-trade/. Accessed on 31 Jan 2020.

Irwin, A. (1995). Citizen science: A study of people expertise and sustainable development. London: Routledge.

Lagares Izidio, L., de Oliveira Cruz, B., Couto, R. M., Novaes, L., \& Farbiarz, J. L. (2018). Design and handicrafts: The importance of interdisciplinarity in collaborative design practice. Strategic Design Research Journal, 11(1), 9-14.

Laws, M. (2015, May 29). Sapelli to tackle illegal cattle invasions for the JuHoansi of NyaeNyae conservancy [Blog]. Extreme citizen science blog. https://uclexcites.blog/2015/05/29/sapelli-totackle-illegal-cattle-invasions-for-the-juhoansi-of-nyae-nyae-conservancy-na/. Accessed on 15 Dec 2020.

Locritani, M., Merlino, S., Abbate, M., \& Nazionale, I. (2019). Assessing the citizen science approach as tool to increase awareness on the marine litter problem. Marine Pollution Bulletin, $140,320-329$.

Moulaert, F., Martinelli, F., Swyngedouw, E., \& González, S. (2005). Towards alternative model (s) of local innovation. Urban Studies, 42(11), 1969-1990.

Mulgan, G. (2006). The process of social innovation. Innovation Technology Government Global, 1 (2), 145-162.

Münkler, H. (2001, July). Buergergesellschaft und Sozialstaat. Paper presented to EnquèteKommission Zukunft des bürgerschaftlichen Engagements, Hall.

Nicolopoulou, K., Karataş-Özkan, M., Vas, C., \& Nouman, M. (2017). An incubation perspective on social innovation: The London Hub - A social incubator. R\&D Management, 47(3), 368-384.

Novak, J., Becker, M., Grey, F., \& Mondardini, R. (2018). Citizen engagement and collective intelligence for participatory digital social innovation. In S. Hecker, M. Haklay, A. Bowser, Z. Makuch, J. Vogel, \& A. Bonn (Eds.), Citizen science: Innovation in open science, society and policy (pp. 124-145). London: UCL Press.

Papageorgiou, F., Kolovou, E., Saridaki, M., Ugolini, F., Rossini, G., Gosselin, E., et al. (2015). INVOLEN. A guide for learning facilitators. Athens: PRISMA Centre for Development Studies.

Pedaste, M., Mäeots, M., Siiman, L. A., de Jong, T., van Riesen, S. A. N., Kamp, E. T., et al. (2015). Phases of inquiry-based learning: Definitions and the inquiry cycle. Educational Research Review, 14, 47-61.

Phills, J. A., Deiglmeier, K., \& Miller, D. T. (2008). Rediscovering social innovation. Stanford Social Innovation Review, 6(4), 34-43.

Putnam, R. D. (2000). Bowling alone: The collapse and revival of American community. New York: Simon \& Schuster Paperbacks.

Responsible Research \& Innovation. (n.d.). European Commission, https://ec.europa.eu/ programmes/horizon2020/en/h2020-section/responsible-research-innovation. Accessed on 21 May 2020.

Ries, L., \& Oberhauser, K. (2015). A citizen army for science: Quantifying the contributions of citizen scientists to our understanding of monarch butterfly biology. Bioscience, 65, 419-430.

Rüede, D., \& Lurtz, K. (2012). Mapping the various meanings of social innovation: Towards a differentiated understanding of an emerging concept. EBS Business School Research Paper Series 12-03. http://ssrn.com/abstract=2091039.

Schild, R. (2016). Environmental citizenship: What can political theory contribute to environmental education practice? The Journal of Environmental Education, 47(1), 19-34.

Schäfer, T., \& Kieslinger, B. (2016). Supporting emerging forms of citizen science: A plea for diversity, creativity and social innovation. Journal of Science Communication, 15(2), Y02. https://doi.org/10.22323/2.15020402. 
Tsai-Hsun, L. (2016). Redesigning public organizational change with care. Design Management Journal, 11, 32-42.

Tsampoulatidis, I., Ververidis, D., Tsarchopoulos, P., Nikolopoulos, S., Kompatsiaris, I., \& Komninos, N. (2013). ImproveMyCity - An open source platform for direct citizen_government communication. In The 21st ACM international conference on multimedia Open source software competition, Barcelona, Catalunya, Spain, October 21-25, 2013, p. 839.

Tsampoulatidis, I., Nikolopoulos, S., Kompatsiaris, I., \& Komninos, N. (forthcoming). Geographic citizen science in citizen-government communication and collaboration: Lessons from the ImproveMyCity application. In A. Skarlatidou \& M. Haklay (Eds.), Geographic citizen science design - No one left behind. London: UCL Press.

Ugolini, F., Massetti, L., Pellegrino, L., Rossini, G., Raschi, A., \& Finato, B. (2016). Environmental education by gaming. Conference proceedings DIDAMATICA2016. Udine, 21-23 April 2016. http://didamatica2016.uniud.it/proceedings/dati/articoli/paper_15.pdf.

Ugolini, F., Cavas, B., Di Grazia, S., Massetti, L., Mylonas, D., Ozdem Yilmaz, Y., et al. (2019). Learning methodology guidelines application of the Pedaste's model in daylighting rivers. Firenze: IBIMET-CNR.

Viñals, R., \& Rodriguez, C. C. P. (Eds.). (2013). Social innovation: New forms of organisation in knowledge-based societies. London: Routledge.

Wang, L., Xia, E., Li, H., \& Wang, W. (2019). A bibliometric analysis of crowdsourcing in the field of public health. International Journal of Environmental Research and Public Health, 16(20), 3825 .

Eglè Butkevičienè is a professor and vice-dean for research in the Faculty of Social Sciences, Arts and Humanities, Kaunas University of Technology. Her research focuses on citizen science, citizen participation, public engagement, social innovations, and social entrepreneurship. She also leads a national project on citizen science for welfare society development.

Artemis Skarlatidou is a senior research associate in the Extreme Citizen Science (ExCiteS) research group at University College London. She has an interdisciplinary academic background in geography, geographic information science, and computer science. Her research interests include human-computer interaction and user experience of geospatial technologies. She was the chair of WG4 in COST Action CA15212.

Bálint Balázs is a senior research fellow and managing director of the Environmental Social Science Research Group (ESSRG). With a background in sociology and environmental sciences, he has research experience in sustainability transitions, policy analysis on sustainable food, cooperative research, public engagement, science-policy dialogues, and participatory action research.

Barbora Duží works at the Department of Environmental Geography, Institute of Geonics AS CR. Her research focuses on societal and geographical aspects of food systems. Currently she explores the role of citizen science in solving environmental and societal issues. She also cooperates with NGOs in environmental education and raising public awareness.

Luciano Massetti has a background in computer science and applied meteorology and climatology and works at the Institute of Bioeconomy of the National Research Council of Italy (IBE-CNR). His research interests are urban climate and urban geometry effects, the effect of climate conditions on human health, light pollution and its effects on nature, and innovative teaching methodologies.

Ioannis Tsampoulatidis holds a BSc in computer science, and he is a PhD candidate on smart cities and collaborative eGovernment at the Aristotle University of Thessaloniki. He is the managing and research director of INFALIA, a spin-off company from the Information Technologies 
Institute of Centre for Research and Technology in Greece. He also manages the development of Improve My City.

Loreta Tauginienè has an interdisciplinary educational background, namely, in the social sciences (law, management) and the humanities (linguistics). Her interests are in preventing research malpractice, including while carrying out research in an innovative manner (e.g. interdisciplinary, citizen science). Co-chair of the WG4 in the COST Action CA15212.

Open Access This chapter is licensed under the terms of the Creative Commons Attribution 4.0 International License (http://creativecommons.org/licenses/by/4.0/), which permits use, sharing, adaptation, distribution and reproduction in any medium or format, as long as you give appropriate credit to the original author(s) and the source, provide a link to the Creative Commons license and indicate if changes were made.

The images or other third party material in this chapter are included in the chapter's Creative Commons license, unless indicated otherwise in a credit line to the material. If material is not included in the chapter's Creative Commons license and your intended use is not permitted by statutory regulation or exceeds the permitted use, you will need to obtain permission directly from the copyright holder. 